\title{
2006-531: CALIFORNIA REGIONAL CONSORTIUM FOR ENGINEERING ADVANCES IN TECHNOLOGICAL EDUCATION
}

\section{Sharlene Katz, California State University-Northridge}

Sharlene Katz is Professor in the Department of Electrical and Computer Engineering at

California State University, Northridge (CSUN) where she has been for over 25 years. She graduated from the University of California, Los Angeles with B.S. (1975), M.S. (1976), and Ph.D. (1986) degrees in Electrical Engineering. Recently, her areas of research interest have been in engineering education techniques and neural networks. Dr. Katz is a licensed professional engineer in the state of California.

\section{Kathleen Alfano, College of the Canyons}

Kathleen Alfano is Director/Principal Investigator of the California Regional Consortium for Engineering Advances in Technological Education (CREATE), an NSF ATE Regional Center for Information and Manufacturing Technology. She graduated from Chestnut Hill College with a B.S. in Chemistry (1976), Purdue University with a M.S. in Education (1981), and the University of California, Los Angeles with a Ph.D. in Higher Education, Work and Adult Development (1993). Dr. Alfano has been on the faculty at College of the Canyons since 1996. 


\section{California Regional Consortium for Engineering Advances in Technological Education (CREATE)}

\section{Background}

The California Regional Consortium for Engineering Advances in Technological Education (CREATE) Center is a joint effort between community colleges, universities and high-tech engineering technology employers. Together, the consortium members serve over 9,000 square miles of coastal and central California. This area served by the members represents a population of over one million. The Center is funded by the National Science Foundation's (NSF) Advanced Technological Education (ATE) program, which is designed to strengthen the preparation of technicians for the high performance workplace of advanced technologies. The Center's goal is to address the needs of industry by producing, as a multi-county consortium, highly skilled and educated technicians to better meet national and State workforce demands in the fields of information and manufacturing technologies.

CREATE was previously funded by two NSF-ATE projects, which met or exceeded all of their objectives. The project had four primary goals, which included curriculum development, enrollment and retention, work-based site experiences and professional development. The CREATE consortium developed programs that began with a common core curriculum in either engineering technology or computer networking. The common core curriculum allowed students to transfer from a participating college to any college in the consortium to take classes in any of the specialty areas offered by the consortium campuses.

The collaborative effort between community colleges, universities, and employers has resulted in a strong regional consortium. The dichotomy between low enrollment in credit electronics programs and the high demand from employers for highly skilled engineering technicians that all colleges experienced in 1997 has changed as a result of the participants' collaborative efforts across institutions and with industry. The change has resulted in an unprecedented level of success for the colleges, their students, and their industry partners because of the effort to align programs with industry standards.

\section{CREATE Center Objectives and Accomplishments}

The CREATE Center, which evolved out of Project CREATE's successes, established objectives, activities, outcomes and timelines designed to target the seven chief areas of need or goals that the CREATE project identified. The CREATE Center's objectives along with the highlights of the Center's accomplishments during its first three years of operation are listed below.

Objective 1: Increase pools of trained teachers for both Information Technology and Manufacturing Technology

An award-winning training program (Hesburgh Certificate of Excellence) at College of the Canyons, with over fifteen years of past success in educating part-time academic faculty has been adapted to a model to train part-time teachers who come from industry or who have only technical skills without teaching backgrounds to be pedagogically strong using workshops based on D.A. Kolb's model of an experiential learning cycle. An emphasis has been placed on the 
needs of community college students. Full-time faculty from regional colleges have been trained to return to their campuses as facilitators for each group of participants, a model adaptable for not only the CREATE region but nationally.

The CREATE consortium has developed a program in which a cohort of faculty receive Facilitator Skills Teaching Workshop training to improve their abilities as facilitators of other faculty's teaching skills and to increase the pool of trained and effective community college technical teachers.

The first workshop, the Teaching Skills Workshop/Teaching Demonstration Facilitator Training was designed for the regional facilitators and included the Teaching Skills Workshop curricula as well as curricula that covered how to design/facilitate a successful workshop experience. A triangulated qualitative assessment was designed to assess this workshop consisting of: daily feedback to instructors, a feedback form designed to encompass the entire session, analysis of facilitator-learner activities to ensure knowledge transfer occurred, six-week follow-up surveys and surveys from participants in the workshops given by facilitator learners as to effectiveness.

The second facilitator workshop for Teaching in the Community College focused on teaching aspects unique to the college teaching experience, particularly as it pertains to community colleges. This workshop assessment was similar in design to that for Teaching Skills Workshop/Teaching Demonstration Facilitator Training.

The Facilitator Development Workshops One and Two have led to successful facilitator trainings within CREATE colleges and are now complete, with at least one full-time faculty able to conduct teacher trainings at each of the CREATE campuses. Several campuses sent more than one faculty to be trained as teaching facilitators. CREATE now continues to disseminate throughout the ATE community and the community colleges nationwide with faculty sponsored by NSF Centers attending from eight states last summer and a waiting list for the next cohort already started. In addition to full-time faculty, industry leaders have begun to attend to learn to act as teaching facilitators at their companies and at community colleges in their area.

Regionally, the trained facilitators have trained 88 part-time adjunct faculty at the seven colleges.

Objective 2: Increase feeder programs from the high school level

Two summer workshops were offered on technical topics emphasizing electronics and robotics specifically designed for high school teachers with little or no industry experience who are interested in infusing pre-information technology and manufacturing technology electronics modules into the high school curricula. Mentoring by full-time community college faculty during the academic year has provided support. Both workshops were assessed to ensure knowledge transfer to participants.

Many activities were computer based using spreadsheet and simulation software. Each workshop attendee was given a toolbox that included electronic components, hardware, and software that can be used for their classroom demonstrations and students use.

In order to better promote CREATE programs to high school students, extensive high school outreach has been undertaken and new materials and videos are being field tested. State funding 
was obtained to develop a video which will be field tested by CREATE in Year Four (05-06). It is being tested with three test groups: high school students at the targeted schools, high school faculty at the targeted schools, and high school parents, administrators and counselors.

Another exciting accomplishment within objective two has been the success of high school after school and summer camps especially targeted at outreach to women and underrepresented. These pilot programs are being expanded to more campuses and students.

Objective 3: Increase Bachelor's level transfer programs that both articulate and are accessible with the new technology Associate degree programs

Five universities agreed to work with CREATE to develop strong articulation with their programs. California State University, Fresno agreed to begin to offer the junior and senior year of a BS program in Industrial Technology on-site at the community college campus, a University Center concept already successfully pilot tested at College of the Canyons. The first cohort of eight students began in Spring 2003 with a target date to complete a BS in Fall 2005. California State University, Channel Islands agreed to begin the process of developing the junior and senior year of a 2+2 BS in Information Technology with a target of curriculum approval through the California Chancellor's Office Master Plan in 2004-2005 and the start of the first class in Fall 2005. CREATE students from multiple colleges were recruited and a tracking system was developed to assess their progress as they completed courses and progressed to degrees through the programs.

A cohort of 19 students is currently on track to be the first B.S. graduating class in 2005-2006 (from CREATE's on-site/on-line hybrid 2+2 program with CSU, Fresno's (CSUF) Industrial Technology program). Another group of 16 have started the new on-site and/or online 2+2 B.S. program in Information Technology at California State University, Channel Islands (CSUCI).

California State University system transferability for the CREATE courses at Allan Hancock College, Moorpark College, Oxnard College, Cuesta College, Santa Barbara City College and College of the Canyons was obtained. Brochures detailing the articulation of CREATE courses with both the $2+2$ B.S. in Industrial Technology and the $2+2$ B.S. in Information Technology program were produced. Community college counselors were trained to advise their students on these two programs.

Objective 4: Create an organized system for developing, documenting, and implementing worksite internship experiences for both Information Technology and Manufacturing Technology

An internship developer was hired and produced over 50 employer contacts and outreach material over a period of five months. However, this effort was postponed during the downturn of the IT industry, with industry all citing downsizing of staff who could supervise interns and the economy in general as a factor. All CREATE community colleges continue to run their own internship programs. In Year 3, a survey of internship programs at each college was performed. It revealed that internships are very geographically dependent. However, a major change occurred in the Spring of 2005 when several IT companies began to work with CREATE on multi-County and multi-State internship and job placement programs. 
Objective 5: Develop, adapt and implement regional programs in network security, wireless and telecommunications technologies and more problem-based, modularized manufacturing technology curricula and standardization

Wireless, networking, and telecommunications technology curricula, emphasizing network security, were developed, pilot tested, and implemented regionally for certification and degree programs. Curricula have been documented for Security and Wireless courses at several of the CREATE colleges. These curricula will be made available for adaptation by other colleges nationally. Enrollment in the new courses created with CREATE support increased in the targeted areas from 66 to 406 students with strong retention rates.

Several electronics and manufacturing technology courses were assessed as examples of projectbased manufacturing technology curricula. All are credit curricula that are adaptable at other colleges. Assessment data has been collected regarding timely implementation of courses and student success has been documented through comparative grade analysis, and completion rates.

A new online DC circuits course was developed and several new labs were put in place to support the manufacturing technology curriculum. Additionally, ten existing traditional courses were converted to online format.

Objective 6: Evaluate and contrast the learning, workplace competencies, and pass rate in industry certification programs of students who complete technical certifications in on-line (learner centered versus traditional) versus in-class formats.

The CREATE regional consortium has plans to develop, pilot test, and offer both in-class and on-line versions of at least two complete wireless and computer networking certificate programs. This work is currently in progress.

Objective 7 Implement a model evaluation that will follow both past and future students as they enter the workplace and/or transfer to measure longitudinally the success of the educational experience.

Formative and summative evaluation processes to measure each of the Center's objectives and outcomes have been used. The results of this evaluation reveal that $51 \%$ of CREATE students are employed 40 hours a week or more and 32\% are employed in the area they are studying in CREATE. $25.93 \%$ of students report that they are seeking knowledge to pass a certificate and roughly $18 \%$ already possess a bachelor's degree. Also of note are the break-out numbers in the unduplicated headcount data that show that while $46 \%$ of all students who take a CREATE course are female, only $14 \%$ of students who complete a certification sequence are female. An analysis of this data is providing the project with target classes for the recruitment of women into the field. Since 1999, 2778 CREATE students have earned Associate degrees and 935 CREATE students have earned certificates.

\section{Summary}

The CREATE consortium, a joint effort between community colleges, universities and high-tech engineering technology employers, is currently in its tenth year of operation. This paper highlights the accomplishments of the past three years (2002-2005) as an NSF ATE Regional 
Center. Through its programs and commitment to partnerships, the CREATE consortium has had a significant impact on students, faculty and colleges in its region including:

- 21 facilitators have trained over 100 faculty members from 15 community colleges in Teaching Skills Workshop, Teaching Demonstration, and Teaching in the Community Colleges across the nation.

- 17,735 students (unduplicated) have completed at least one CREATE credit course since 1999.

- 2,778 CREATE students have earned Associate degrees and 935 students have earned a certificate since 1999.

- $46 \%$ of degree or certificate recipients were female; $19 \%$ were Latino.

- Increased access to B.S. degree through online and hybrid courses at CSU Channel Islands and CSU Fresno.

The CREATE Center continues to operate in its fourth year as an NSF ATE Regional Center (2005/2006) with modified objectives. Further information on CREATE can be found on our website at: http://www.create-california.org. 